\title{
Patient perspectives on switching disease-modifying therapies in the NARCOMS registry
}

This article was published in the following Dove Press journal:

Patient Preference and Adherence

4 July 2014

Number of times this article has been viewed

\author{
Amber R Salter' \\ Ruth Ann Marrie 2,3 \\ Neetu Agashivala ${ }^{4}$ \\ Daniel A Belletti ${ }^{4}$ \\ Edward Kim ${ }^{4}$ \\ Gary R Cutter' \\ Stacey S Cofield' \\ Tuula Tyry 5 \\ 'Department of Biostatistics, \\ University of Alabama at Birmingham, \\ Birmingham, AL, USA; ${ }^{2}$ Department \\ of Internal Medicine, ${ }^{3}$ Department \\ of Community Health Sciences, \\ University of Manitoba, Winnipeg, MB, \\ Canada; ${ }^{4}$ Novartis Pharmaceutical \\ Corporation, East Hanover, NJ, USA; \\ ${ }^{5}$ Division of Neurology, St. Joseph's \\ Hospital and Medical Center, Phoenix, \\ AZ, USA
}

Introduction: The evolving landscape of disease-modifying therapies (DMTs) for multiple sclerosis raises important questions about why patients change DMTs. Physicians and patients could benefit from a better understanding of the reasons for switching therapy.

Purpose: To investigate the reasons patients switch DMTs and identify characteristics associated with the decision to switch.

Method: The North American Research Committee on Multiple Sclerosis (NARCOMS) Registry conducted a supplemental survey among registry participants responding to the 2011 update survey. The supplemental survey investigated reasons for switching DMT, origin of the discussion of DMT change, and which factors influenced the decision. Chi-square tests, Fisher's exact tests, and logistic regression were used for the analyses.

Results: Of the 691 eligible candidates, 308 responded and met the inclusion criteria (relapsing disease course, switched DMT after September 2010). The responders were $83.4 \%$ female, on average 52 years old, with a median (interquartile range) Patient-Determined Disease Steps score of 4 (2-5). The most recent prior therapy included first-line injectables $(74.5 \%)$, infusions $(18.1 \%)$, an oral DMT (3.4\%), and other DMTs (4.0\%). The discussion to switch DMT was initiated almost equally by physicians and participants. The primary reason for choosing the new DMT was based most frequently on physician's recommendation $(24.5 \%)$ and patient perception of efficacy (13.7\%).

Conclusion: Participants frequently initiated the discussion regarding changing DMT, although physician recommendations regarding the specific therapy were still weighed highly. Long-term follow-up of these participants will provide valuable information on their disease trajectory, satisfaction with, and effectiveness of their new medication.

Keywords: multiple sclerosis, health communication

\section{Introduction}

With the advent of new immunological therapies for the treatment of multiple sclerosis (MS), the complexity of managing disease-modifying therapies (DMTs) has increased. The first-line injectable DMTs, including interferon $\beta$ and glatiramer acetate, have been available for almost 20 years; they have known adverse events and benefits. ${ }^{1}$ Newer therapies have different risk-benefit profiles compared to the first-line therapies, but all are used to prevent relapses, increase in lesion burden, and progression of disability. ${ }^{1}$ Physicians managing DMTs must consider many factors, including how to tailor therapy to the needs of the individual patient. ${ }^{2}$

The evaluation of which drug is appropriate for which patient is challenging for the physician and patient, especially in the event of relapses or progression while
Correspondence: Amber R Salter Department of Biostatistics, University of Alabama at Birmingham, 1665 University Blvd, Room 327, Birmingham, AL 35294-0022, USA

Tel +l 2059344340

Fax + I 205975 254 I

Email asalter@uab.edu 
on a DMT. Switching among DMTs in the case of breakthrough disease appears to be common practice. ${ }^{2}$ Adverse events, adherence, cost, and risk tolerances are all important considerations in the decision to switch medications ${ }^{3}$ even at similar disability levels, the importance of these factors on decision-making varies between patients. ${ }^{2}$

Increasingly, clinicians and researchers recognize the importance of and need for shared decision-making in complex treatment decisions. ${ }^{4,5}$ Therefore, understanding of the patient perspective regarding their rationale and motivation for switching DMTs is important, as is assessing differences in sociodemographic factors and disease characteristics among the participants switching to different DMTs. Our exploratory hypothesis was that there would be clinical and sociodemographic differences between those participants who initiated a switch compared to the physician-initiated switchers, and that the differences may depend on the DMT group to which the participant switched.

\section{Methods}

North American Research Committee on Multiple Sclerosis (NARCOMS) registry

The NARCOMS registry is a voluntary, self-report registry of persons with MS. The diagnosis of MS has been validated in a random sample of registry participants. ${ }^{6}$ Participants complete an enrollment survey and update their clinical and sociodemographic information through semi-annual surveys. Although the NARCOMS registry is not population-based, the characteristics of the registry population are similar to those reported for other MS populations, ${ }^{7,8}$ and other MS volunteer samples have been found to be representative of the wider population of persons with MS. ${ }^{9}$

\section{Patient's Perspective survey}

NARCOMS mailed a "Patient's Perspective" supplemental survey to those registry participants who had reported switching a DMT in the 2011 spring or fall surveys. Inclusion criteria for the analyses were based on NARCOMS update survey information and the returned supplemental survey, and were 1) a relapsing disease course, and 2) affirmative response to a single question about whether their DMT had changed in the past 6 months, after September 2010. Participants identified their current DMT and the length of use, frequency of administration, and perceived efficacy of that DMT. Also, participants reported which DMT they had taken immediately prior to their current DMT, and how long they were on that DMT. The primary reasons for making the decision to switch were recorded (Figure 1A). In addition to the primary reasons for switching, secondary reasons were also of interest. To identify secondary reasons for the switching decision, we provided the same response options as for the primary reasons but allowed respondents the option to select as many as were applicable. The participants who initiated the discussion to switch were asked their reasons for the initiation of the discussion with their physician (Figure 1B). The response options for both sets of questions were related to efficacy, safety, side effects, and medical tolerance.

\section{Analysis}

Sociodemographic and clinical information of all study participants were gathered from the standard survey information already collected in the NARCOMS registry. Race was included as a dichotomous variable: Caucasian (reference group), and non-Caucasian. Education was analyzed as a categorical variable: high school diploma or less (reference group); associate's degree or technical degree; bachelor's degree; or postgraduate degree, as was annual household income (USD): $<\$ 15,000$ (reference group); $\$ 15,000-$ $\$ 29,999 ; \$ 30,000-\$ 49,999 ; \$ 50,000-\$ 100,000 ;>\$ 100,000$; or declined to answer. Insurance status was categorized as private, public only (reference group), or none.

The Patient-Determined Disease Steps (PDDS) score, relapse history, and symptom worsening are routinely collected in NARCOMS surveys. The PDDS is a validated 9-point self-report measure, which correlates highly with the expanded disability status scale (EDSS). ${ }^{10-12}$ It is an ordinal scale ranging from 0 (normal, reference group) to 8 (bedbound). Participants report relapses that occurred in the prior 6 months and whether their MS symptoms worsened in a gradual, progressive manner over the past 6 months. These variables were used, when available, for the years preceding the switch. Providers managing care included MS specialist, neurologist (reference group), general neurologist, primary health care provider, and other. Data from the fall 2011 update survey were used to verify the specific DMT changes reported by the participant in the Patient's Perspective survey, which was administered approximately 3 months later.

The DMTs were categorized as first-line injectables (interferon $\beta$-1a, interferon $\beta$ - $1 \mathrm{~b}$, glatiramer acetate); oral therapies (fingolimod); infusion therapies (natalizumab, rituximab, alemtuzumab, daclizumab), although no participant switched to rituximab, alemtuzumab, or daclizumab; or other (eg, IVIG [intravenous immunoglobulin] and combinations of DMTs). Data on current and past DMT use reported on the supplemental surveys were utilized to verify eligibility 
A

What was the main reason for choosing your current disease modifying therapy over other options? Please choose ONE.

\begin{tabular}{|c|c|}
\hline Efficacy & - Efficacy (how well the medication works) \\
\hline Side effects & - Side effect profile \\
\hline Safety & $\begin{array}{l}\text { - Safety } \\
\text { - Results of JCV antibody test (assessing risk profile for PML) }\end{array}$ \\
\hline $\begin{array}{l}\text { Medication } \\
\text { tolerance }\end{array}$ & $\begin{array}{l}\text { - Dislike of injections/infusions } \\
\text { - Convenience }\end{array}$ \\
\hline Other & $\begin{array}{l}\text { - Nothing else available } \\
\text { - Doctor's recommendation } \\
\text { - Insurance coverage } \\
\text { - } \text { Cost } \\
\text { - Pregnancy or nursing } \\
\text { - Other (specify) }\end{array}$ \\
\hline
\end{tabular}

B

\begin{tabular}{|c|c|}
\hline Efficacy & - I felt my current therapy was not effective enough \\
\hline Side effects & - I didn't like the side-effects \\
\hline Safety & $\begin{array}{l}\text { - I had safety concerns } \\
\text { - I read about problems with the drugs I was taking on the internet } \\
\text { - I saw/read/heard about problems with the drug I was on elsewhere }\end{array}$ \\
\hline $\begin{array}{l}\text { Medication } \\
\text { tolerance }\end{array}$ & - I didn't like the route of administration of my current therapy \\
\hline Other & $\begin{array}{l}\text { - I read about other treatment options on the internet } \\
\text { - I saw/read/heard about other treatment options elsewhere } \\
\text { - My family or friends suggested I try a different therapy } \\
\text { - Other reason (specify) }\end{array}$ \\
\hline
\end{tabular}

Figure I Response options for specific questions in the NARCOMS Patient's Perspective survey.

Notes: (A) Decision (asked of all participants). (B) Discussion (asked only of participant-initiated switchers).

Abbreviations: JCV, John Cunningham virus; NARCOMS, North American Research Committee on Multiple Sclerosis; PML, progressive multifocal leukoencephalopathy.

for study inclusion and the past semi-annual survey data were used for confirmation. Type and duration of current and past DMT use were covariates in the analyses.

We summarized categorical variables using frequency (percent) and continuous variables using mean (standard deviation) or median (interquartile range [IQR]) as appropriate. Missing responses were not imputed. Univariate comparisons among DMT groups and among the physicianinitiated and participant-initiated switchers used chi-square tests and Fisher's exact tests for categorical variables (sex, race, doctor managing the participant's MS, and past and switched-to DMT); Wilcoxon test for median PDDS score; and analysis of variance for continuous variables (age and disease duration). Logistic regression was used to compare differences in clinical and sociodemographic factors between those participants who would consider switching again and those who would not. Dependent variables were selected from those in Table 1 and the variable was kept in the model if $P<0.05$. An alpha level $<0.001$ was used for these analyses in order to limit the number of false positive tests due to the multiple tests being conducted. Analyses were performed using SAS software (v9.2; SAS Institute Inc., Cary, NC, USA).

\section{Standard protocol approvals, registrations, and patient consent}

NARCOMS participants agree to the use of their de-identified data for research purposes. The semi-annual surveys and 
Table I Sample characteristics

\begin{tabular}{|c|c|c|c|c|}
\hline Characteristic & $\begin{array}{l}\text { All } \\
(n=308)\end{array}$ & $\begin{array}{l}\text { First-line injectables } \\
(n=109)\end{array}$ & $\begin{array}{l}\text { Infusions } \\
(n=7 I)\end{array}$ & $\begin{array}{l}\text { Oral therapies } \\
(n=128)\end{array}$ \\
\hline Female, n (\%) & $257(83.4)$ & $95(87.2)$ & $60(84.5)$ & $102(79.7)$ \\
\hline Caucasian, n (\%) & $267(97.1)$ & $98(98.0)$ & $62(96.9)$ & $107(96.4)$ \\
\hline \multicolumn{5}{|l|}{ Education level, n (\%) } \\
\hline High school or less & $89(29.0)$ & $31(28.4)$ & $17(24.3)$ & $41(32.0)$ \\
\hline Associate's or technical degree & $51(16.6)$ & $21(19.3)$ & II (I5.7) & $19(14.8)$ \\
\hline Bachelor's degree & $89(29.0)$ & $32(29.4)$ & $20(28.6)$ & $37(28.9)$ \\
\hline Postgraduate degree & $78(25.4)$ & $25(22.9)$ & $22(31.4)$ & $31(24.2)$ \\
\hline \multicolumn{5}{|l|}{ Annual income (USD), n (\%) } \\
\hline$<\$ 15,000$ & $23(7.6)$ & $9(8.3)$ & $3(4.3)$ & II (8.7) \\
\hline$\$ 15,000-\$ 29,999$ & $4 \mid(13.5)$ & $16(14.8)$ & II (I5.7) & $14(1 \mathrm{l} . \mathrm{I})$ \\
\hline$\$ 30,000-\$ 49,999$ & $40(13.2)$ & $17(15.7)$ & $10(14.3)$ & $13(10.3)$ \\
\hline$\$ 50,000-\$ 100,000$ & $85(28.0)$ & $33(30.6)$ & $18(25.7)$ & $34(27.0)$ \\
\hline$>\$ 100,000$ & $60(19.7)$ & $15(13.9)$ & I5 (2I.4) & $30(23.8)$ \\
\hline Declined to answer & $55(18.1)$ & $18(16.7)$ & $13(18.6)$ & $24(19.0)$ \\
\hline \multicolumn{5}{|l|}{ Health insurance, $\mathrm{n}(\%)$} \\
\hline Private & $227(74.4)$ & $77(72.0)$ & $53(74.6)$ & $97(76.4)$ \\
\hline Public only & $70(23.0)$ & $27(25.2)$ & $15(21.1)$ & $28(22.0)$ \\
\hline None & $8(2.6)$ & $3(2.8)$ & $3(4.2)$ & $2(1.6)$ \\
\hline Age (years), mean (SD) & $52(9.7)$ & $52.2(10.3)$ & $50.2(10.9)$ & $52.1(8.4)$ \\
\hline Disease duration (years), mean (SD) & I3.9 (8.6) & $13.2(7.7)$ & I3.3 (9.8) & I $4.8(8.5)$ \\
\hline PDDS score, median (IQR) & $4(2-5)$ & $4(2-5)$ & $4(2-5)$ & $3(I-5)$ \\
\hline \multicolumn{5}{|l|}{ MS type, n (\%) } \\
\hline RRMS & $218(70.8)$ & $80(73.4)$ & $49(69.0)$ & $89(69.5)$ \\
\hline SPMS & $62(20.1)$ & $22(20.2)$ & $13(18.3)$ & $27(2 I . I)$ \\
\hline Unsure & $25(8.1)$ & $7(6.4)$ & $9(12.7)$ & $9(7.0)$ \\
\hline RRMS/SPMS & $3(1.0)$ & - & - & $3(2.3)$ \\
\hline \multicolumn{5}{|l|}{ Provider managing care, $\mathrm{n}(\%)$} \\
\hline Neurologist, MS specialist & $208(68.9)$ & $71(65.7)$ & $51(72.9)$ & $86(69.4)$ \\
\hline Neurologist, non-MS specialist & $56(18.5)$ & $20(18.5)$ & $10(14.3)$ & $26(21.0)$ \\
\hline Primary health care provider & $20(6.6)$ & $7(6.5)$ & $5(7.1)$ & $8(6.5)$ \\
\hline Other & $18(6.0)$ & $10(9.3)$ & $4(5.7)$ & $4(3.2)$ \\
\hline
\end{tabular}

Abbreviations: IQR, interquartile range; MS, multiple sclerosis; PDDS, Patient-Determined Disease Steps; RRMS, relapsing-remitting MS; SD, standard deviation; SPMS, secondary-progressive MS; USD, US dollars.

the supplemental survey were approved by the University of Alabama at Birmingham (Birmingham, AL, USA) institutional review board.

\section{Results}

There were 10,591 unique registry participants who responded to at least one of the two routine surveys in 2011 and, of these participants, $40.5 \%$ reported not taking any DMT. Six hundred and ninety-one $(6.5 \%$ of the total or $10.9 \%$ of those taking a DMT) reported switching DMTs and were sent the supplemental survey (Figure 2). From those 691 potential candidates, $470(68.6 \%)$ responded. Thirty-four percent $(n=162)$ of responders did not fully meet the inclusion criteria: ten were participating in a clinical trial for a DMT not currently approved by the US Food and Drug Administration (FDA); 73 switched before September 2010; 67 did not actually change medication (ie, had dose or frequency changes or stopped medication); and 12 described themselves as experiencing a primary progressive disease course. Responders ( $\mathrm{n}=470)$ were more likely to be Caucasian ( $P=0.007)$, older $(P=0.0009)$, and to have a slightly longer disease duration $(P=0.005)$ than nonresponders. However, when comparing the analysis participants $(n=308)$ to the nonresponders, no differences in disease duration $(P=0.11)$ or age $(P=0.08)$ were seen, and the nonresponders were less likely to be Caucasian $(P=0.006)$.

The study participants included in the analyses $(\mathrm{n}=308)$ were primarily female $(83.4 \%)$, and over one-half were at or above a disability level requiring the use of a cane (PDDS score $\geq 4$ ) (Table 1). This subset was representative of the active registry participants and of persons with MS who have had the disease for more than 10 years. ${ }^{7,13,14}$ The respondents were taking first-line injectable (109, 35.4\%), infusion $(71,23.1 \%)$, and oral $(128,41.6 \%)$ DMTs. For comparison, the distribution of DMTs for the fall 2011 survey $(n=8,707)$ shows that $53.2 \%$ of responders were taking 


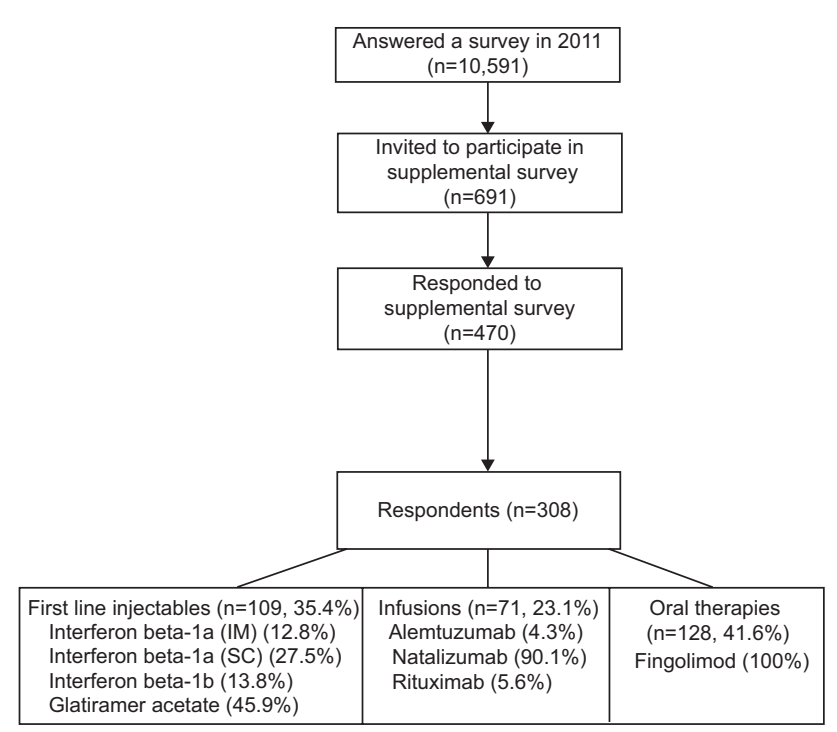

Figure 2 Cohort selection diagram.

Abbreviations: IM, intramuscular; SC, subcutaneous.

a first-line injectable DMT, 8.6\% were taking an infusion DMT, and 3.2\% were taking an oral DMT. None of the factors in Table 1 differed by the current DMT group. Overall, three-quarters of participants had been on their prior DMT for 1 year or more prior to switching. Of those switching to first-line injectables, $69.5 \%$ had been on their prior DMT for 1 year or more, while $85.7 \%$ of those switching to infusions and $81.3 \%$ of those switching to oral DMTs had been on their prior DMT for 1 year or more. Most participants who switched to a first-line injectable DMT (73.3\%) had been taking another first-line injectable immediately prior to the switch, as had those who switched to an oral (66.7\%) or infusion $(90.0 \%)$ DMT.

\section{Initiating differences}

The origin of the discussion to switch was split almost equally between the participant initiating the conversation $(49.0 \%)$ and the physician suggesting the idea (48.7\%); $1.3 \%$ selected both choices $(n=4)$. There were no differences in demographic and clinical factors and most recent past DMT; however, a higher proportion of participants initiated the discussion when switching to an oral DMT compared to those switching to a first-line injectable or infusion therapy (Table 2). The four participants who selected both themselves and their physician as having initiated the discussion had switched to an oral DMT. Of those participants who had initiated the discussion to switch with their physician, 39\% reported asking because of adverse effects and $32.9 \%$ because of the participant-reported, perceived lack of effectiveness of their past DMT (see the Discussion section and Figure 1).

\section{Switching-associated factors}

While there may be many factors that motivate participants to switch DMT, the survey aimed to identify the main reason for the change in DMT. Overall, doctor's recommendation $(75,24.5 \%)$ was the most frequently reported main reason to switch DMT, followed by perceived lack of efficacy (42, $13.7 \%$ ). Table 3 shows the variation in the main reasons for switching from the most immediate past DMT stratified by current DMT. The main reasons for switching were similar between the physician-initiated and the participant-initiated switchers, with the exception of the patient-initiated switchers having a lower proportion (11.0\% versus $39.2 \%)$ of switching primarily because of the doctor's recommendation and a higher proportion (17.1\% versus $4.7 \%$ ) of switching because of a dislike of the infusions or injections (Table 2). Other reasons considered by over $30 \%$ of participants for switching included adverse effects and lack of efficacy.

We also asked about other issues surrounding the decision to switch. Currently, $74 \%$ of the participants would not consider switching back to their previous medications or trying something else. Stratified by current DMT group, those on an oral DMT were more likely to prefer staying on their DMT $(81.3 \%)$ than those on infusion DMT $(77.5 \%)$ or first-line injectables $(63.6 \%)(P=0.005)$. However, those on an oral DMT were also the most likely to have initiated the discussion to switch DMTs. A large proportion of participants (89\%) felt they had adequate information about their new treatment at the time of the switch. Only $14.4 \%$ reported using information on the internet as the basis for initiating the discussion. In terms of changing DMT again, those taking a first-line injectable were 2.6 (95\% confidence interval [CI]: $[1.45,4.91])$ and 2.1 (95\% CI [1.04, 4.2]) times more likely to consider switching back than those taking an oral ( $P=0.0014)$ or infusion $(P=0.039)$ DMT, respectively.

\section{Clinical factors}

Respondents' clinical status was investigated using relapse and symptom worsening history from the year prior to the switch. Overall ( $\mathrm{n}=237), 47.3 \%$ of switchers reported relapse activity in the year prior; $59.5 \%$ reported symptom worsening in 2010; and $76.0 \%$ reported having either relapse activity or symptom worsening (ie, disease activity). No differences in having disease activity were found between DMT groups $(P=0.70)$. Participants who initiated the switch did not differ from physician-initiated switchers regarding reported disease activity $(P=0.35)$. The median (IQR) PDDS score was higher for those with activity (4 [2-5]) and those without 
Table 2 Comparison of demographic and clinical factors between participant- and physician-initiated switchers

\begin{tabular}{|c|c|c|c|}
\hline & $\begin{array}{l}\text { Participant-initiated } \\
(n=146)\end{array}$ & $\begin{array}{l}\text { Physician-initiated } \\
(n=\mid 48)\end{array}$ & $P$-value \\
\hline Female, n (\%) & $118(8 I)$ & $127(86)$ & 0.25 \\
\hline Caucasian, n (\%) & $124(96)$ & $130(98)$ & 0.45 \\
\hline Age (years), mean (SD) & $51.7(8.9)$ & $5 \mathrm{I} .4(10.5)$ & 0.79 \\
\hline Disease duration (years), mean (SD) & I3.5 (7.3) & I3.7 (9.4) & 0.81 \\
\hline \multicolumn{4}{|l|}{ PDDS score, n (\%) } \\
\hline 0 (normal) & $15(10)$ & $15(10)$ & 0.19 \\
\hline I (mild disability) & $18(12)$ & $20(14)$ & \\
\hline 2 (moderate disability) & $18(12)$ & $9(6)$ & \\
\hline 3 (gait disability) & $26(18)$ & $21(14)$ & \\
\hline 4 (early cane) & $30(21)$ & $37(25)$ & \\
\hline 5 (late cane) & $21(14)$ & $15(10)$ & \\
\hline 6 (bilateral support) & $13(9)$ & $19(13)$ & \\
\hline 7 (wheelchair/scooter) & $5(3)$ & $12(8)$ & \\
\hline \multicolumn{4}{|l|}{ Physician managing MS, n (\%) } \\
\hline Neurologist, MS specialist & $102(7 \mid)$ & $100(68)$ & 0.06 \\
\hline Neurologist, non-MS specialist & $30(2 I)$ & $24(16)$ & \\
\hline Primary care physician & $9(6)$ & $10(7)$ & \\
\hline Other & $3(2)$ & $13(9)$ & \\
\hline \multicolumn{4}{|l|}{ DMT switched to, n (\%) } \\
\hline First-line injectable & $48(33)$ & $56(38)$ & 0.03 \\
\hline Infusion therapy & $27(18)$ & $4 \mid(28)$ & \\
\hline Oral DMT & 71 (49) & $51(34)$ & \\
\hline \multicolumn{4}{|l|}{ Past DMTs, n (\%) } \\
\hline First-line injectable & $106(75)$ & $109(75)$ & 0.62 \\
\hline Infusion therapy & $23(16)$ & $27(19)$ & \\
\hline Oral DMT & $4(3)$ & $5(3)$ & \\
\hline Other & $8(6)$ & $4(3)$ & \\
\hline \multicolumn{4}{|l|}{ Main reason for switching, $\mathrm{n}(\%)$} \\
\hline Doctor's recommendation & $16(11.0)$ & $58(39.2)$ & 0.27 \\
\hline Side effect profile & $16(11.0)$ & $11(7.4)$ & \\
\hline Dislike of injections/infusions & $25(17.1)$ & $7(4.7)$ & \\
\hline Efficacy & $20(13.7)$ & $19(12.8)$ & \\
\hline Safety & $7(4.8)$ & $7(4.7)$ & \\
\hline Results of JCV antibody test & I $(0.7)$ & $6(4.1)$ & \\
\hline Convenience & II (7.5) & $2(1.4)$ & \\
\hline Cost & I $(0.7)$ & $\mathrm{I}(0.7)$ & \\
\hline Insurance coverage & $\mathrm{I}(0.7)$ & $3(2.0)$ & \\
\hline Nothing else available & $5(3.4)$ & $8(5.4)$ & \\
\hline Other & $21(14.4)$ & II (7.4) & \\
\hline Multiple answered & $21(14.4)$ & $14(9.5)$ & \\
\hline Not answered & I (0.7) & I $(0.7)$ & \\
\hline
\end{tabular}

Abbreviations: JCV, John Cunningham virus; DMT, disease-modifying therapy; MS, multiple sclerosis; PDDS, Patient-Determined Disease Steps; SD, standard deviation.

activity $(2[1-4])$ (Wilcoxon, $P=0.005)$. The main reasons for switching among those with no disease activity were doctor's recommendation (21.1\%) and dislike of injections/ infusions $(17.5 \%)$, while the main reasons for switching among those with some activity were doctor's recommendation (27.5\%) and adverse effects (15.7\%). Figure $3 \mathrm{~A}$ and $\mathrm{B}$ compare clinical status for physician-initiated and participant-initiated switches by DMT group. When looking within a current DMT group, participant-initiated switchers currently taking either first-line injectables or oral DMTs had a higher proportion with no relapse activity with a similar proportion reporting no relapse activity in the physician-initiated switchers on first-line injectables $(P=0.009)$. The absence of reported symptom worsening did not differ within DMT groups between participant-initiated switchers and physician-initiated switchers $(P=0.15)$.

\section{Other areas of interest}

Almost $85 \%$ of responders ranked the physician managing their MS as the most trusted source of treatment option 


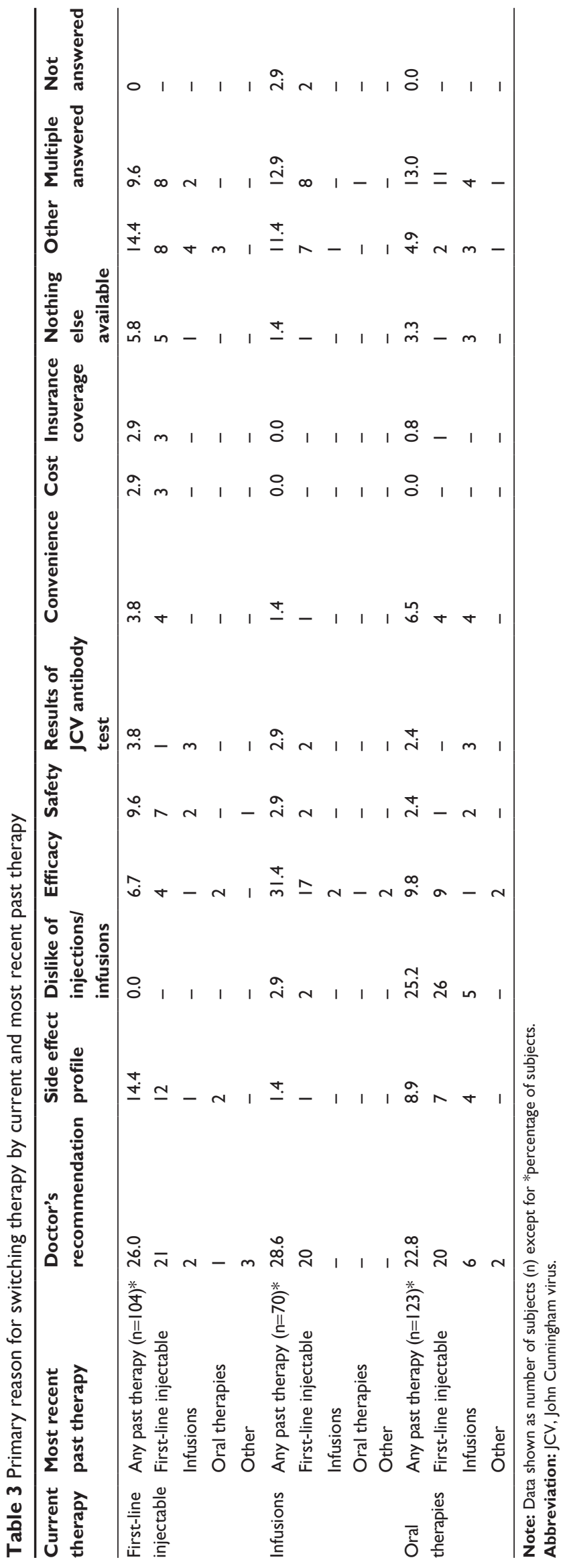

\section{A}

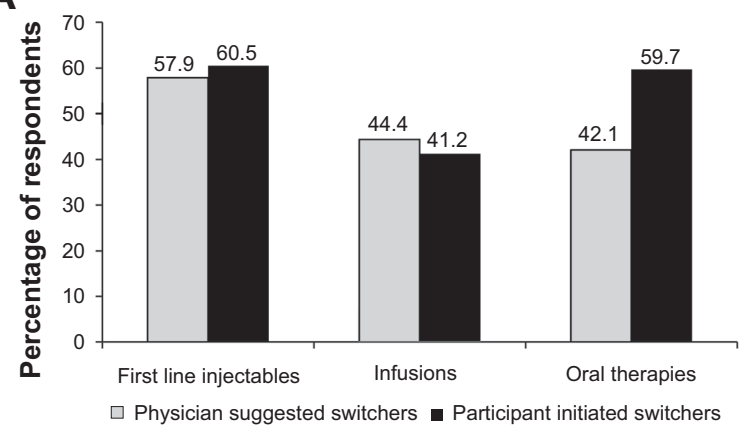

B

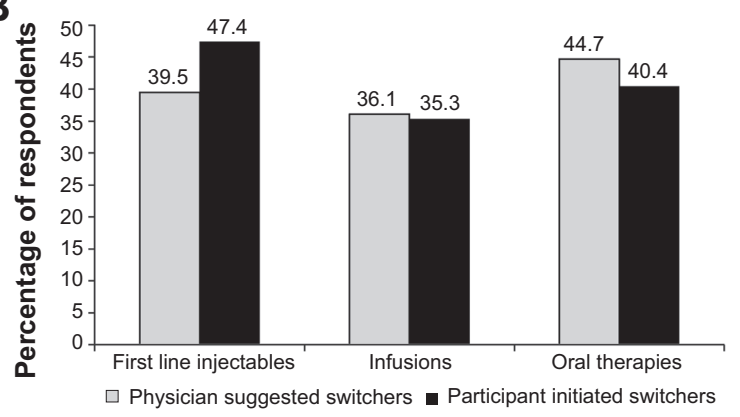

Figure 3 Relapse activity and reported symptom worsening by DMT group and initiating group.

Notes: (A) Proportion with no reported relapse activity in the year prior to switch within the current DMT group by initiating group (physician or participant) $(P=0.009)$. (B) Proportion with no reported symptom worsening in the year prior to switch within the current DMT group by initiating group (physician or participant) $(P=0.15)$.

information. Among those who ranked their doctor as one of their most trusted sources (first, second, or third), there were no statistically significant differences by the current DMT group or by the type of physician managing their MS. After a median of 7-12 months on their current DMT, 38\% of responders $(13.6 \%$ on first-line injectables, $7.5 \%$ on an infusion DMT, $16.9 \%$ on an oral DMT) were unsure or considered it too early to rate the effectiveness of the new DMT to which they had switched. Among those who did rate the effectiveness, $44.6 \%$ of first-line injectable, $45.8 \%$ of infusion, and $56.9 \%$ of oral DMT users perceived their current DMT to be very or extremely effective $(P=0.29)$.

\section{Discussion}

We described the patient's perspectives on issues surrounding the decision to switch DMTs. The results reflect the experience of individuals who have had MS for an average of 14 years (range: $1-47$ years) with comparable sociodemographic characteristics across the DMT groups. Responders reported taking a substantial role in initiating the discussion of changing their DMT. While patients with MS were clearly involved in discussing changes in DMT, treatment recommendations and medication information provided by treating physicians played an important role in the choice 
of DMT. Strikingly, the reasons for switching DMT were similar whether the switch was initiated by the participant or the physician.

Little information is available regarding the patient perspectives about switching DMTs, quantifying issues of importance, and potentially identifying appropriate opportunities to initiate conversations regarding alternatives. This makes it necessary for physicians to rely on their own possibly limited experience and clinical guidelines. Consensus papers may provide a summary of what a group feels is reasonable to warrant a switch, but the papers may not encompass all scenarios a physician may encounter nor address patient perspectives. Shared decision-making (SDM) has emerged as a concept that focuses on patient and physician communication in the medical decision-making process and is well suited to practice in MS. ${ }^{15,16}$ SDM involves the exchange of information between the physician and patient, where physicians contribute experience and information while the patient communicates their values, risk attitudes, and treatment goals. ${ }^{4,15,17}$ Heesen et $\mathrm{al}^{15}$ found that $80 \%$ of MS patients in pilot studies wanted an autonomous role in the decision-making process. Involving and educating the patient in the SDM process improves health outcomes and quality of life in other chronic diseases such as diabetes. ${ }^{18}$ While the desire for a shared role in management is not universal with all MS patients, its importance will likely increase in the management of MS over time as treatment options and evidence for outcomes evolve. This study shows that patients from a sociodemographically diverse population already play an active role in some form of SDM regarding the switching of their treatments.

This study has several limitations. There were nonresponders to the switching survey and responders who did not qualify for this study, and this represents a potential source of bias. However, the nonresponders are comparable to those participants included in the analysis, and those excluded from the study are likely to include those who did not actually switch DMTs. Refinement of the single switching question may be needed to more accurately capture future switchers in the database. Also, there is likely to be recall error in the participants' answers; however, we attempted to minimize this potential bias by including only recent switchers. The physician perspective regarding switching was not captured in this study and would provide additional important information in future studies, especially if it could be obtained for specific patient and physician dyads to compare the perspectives regarding the same treatment decision. This study did not evaluate the impact of switching on outcomes, or whether this differed by reason for switching.
Previous studies have examined clinical outcomes after switching DMTs when breakthrough disease occurs, a paradigm that will continue to change with the increase in treatment options. ${ }^{19-21}$ Patients who switched prior to the availability of oral DMTs may have switched for different reasons than those who switch with other treatment options available (ie, perceived convenience). Longitudinal follow-up of these registry participants will provide valuable information on both their disease trajectory, reasons for switching, satisfaction with the chosen therapy, and effectiveness of their new medication.

\section{Acknowledgments}

NARCOMS is supported by the Consortium of Multiple Sclerosis Centers (CMSC) and its Foundation. This study was supported by Novartis Pharmaceuticals Corporation.

\section{Disclosure}

Amber R Salter has received personal compensation from GlaxoSmithKline for data safety monitoring committee services (DSMB). Dr Ruth Ann Marrie has conducted clinical trials for Sanofi-Aventis, and has received research funding from CIHR, PHAC, MHRC, MS Society of Canada, MS Scientific Research Foundation, CMSC Foundation, and Rx \& D Health Research Foundation. She is on the editorial board of Neurology and Multiple Sclerosis Journal. Neetu Agashivala is employed by Novartis Pharmaceuticals Corporation. Daniel A Belletti was employed by Novartis Pharmaceuticals Corporation when this study was conducted. Dr Edward Kim is employed by Novartis Pharmaceuticals Corporation. Dr Gary R Cutter serves on data safety monitoring committees for Antisense Therapeutics Limited, SanofiAventis, Bayhill Pharmaceuticals, Bayer Pharmaceuticals, BioMS Pharmaceuticals, Daichi-Sankyo, GlaxoSmithKlein Pharmaceuticals, Genmab Biopharmaceuticals, Medivation, Peptimmune, PTC Therapeutics, Teva, Vivus, NHLBI, NINDS, and National MS Society, and receives consulting or speaking fees from Alexion, Accentia, BaroFold, Ciba Vision, Biogen Idec, Novartis, Consortium of MS Centers, Klein Buendel Incorporated, Ono Pharmaceuticals, Somnus Pharmaceuticals, Teva, Biogen Idec, Advanced Health Media, EMD Serono, EDJ Associates, Aegis Creative Marketing, Eli Lilly, UT Southwestern University, Klein Buendel, University of Illinois Health Policy Center, and Somnus Therapeutics. Dr Stacey S Cofield received personal compensation from GlaxoSmithKline, TEVA Pharmaceuticals, Orthotech Biotech, the Department of Defense, and the American Academy for Orthopedic Surgery for consulting 
services, research funds, and/or data safety monitoring board service. The authors report no other conflicts of interest in this work.

\section{References}

1. Castro-Borrero W, Graves D, Frohman TC, et al. Current and emerging therapies in multiple sclerosis: a systematic review. Ther Adv Neurol Disord. 2012;5(4):205-220.

2. Rudick RA, Polman $\mathrm{CH}$. Current approaches to the identification and management of breakthrough disease in patients with multiple sclerosis. Lancet Neurol. 2009;8(6):545-559.

3. Fox R, Salter A, Alster J, et al. Risk tolerance in MS patients: survey results from the NARCOMS registry. Neurology. 2011;76(9):S4.

4. Giovannoni G, Rhoades RW. Individualizing treatment goals and interventions for people with MS. Curr Opin Neurol. 2012;25 Suppl: S20-S27.

5. Heesen C, Kasper J, Segal J, Köpke S, Mühlhauser I. Decisional role preferences, risk knowledge and information interests in patients with multiple sclerosis. Mult Scler. 2004;10(6):643-650.

6. Marrie RA, Cutter G, Tyry T, Campagnolo D, Vollmer T. Validation of the NARCOMS registry: diagnosis. Mult Scler. 2007;13(6):770-775.

7. Jacobs LD, Wende KE, Brownscheidle CM, et al. A profile of multiple sclerosis: the New York State Multiple Sclerosis Consortium. Mult Scler. 1999;5(5):369-376.

8. Weinshenker BG, Bass B, Rice GP, et al. The natural history of multiple sclerosis: a geographically based study. I. Clinical course and disability. Brain. 1989;112(Pt 1):133-146.

9. Taylor BV, Palmer A, Simpson S Jr, Lucas R; NZMSPS study group, Simmons RD, Mason D, et al. Assessing possible selection bias in a national voluntary MS longitudinal study in Australia. Mult Scler. 2013;19(12):1627-1631.

10. Hohol MJ, Orav EJ, Weiner HL. Disease steps in multiple sclerosis: a longitudinal study comparing disease steps and EDSS to evaluate disease progression. Mult Scler. 1999;5(5):349-354.
11. Marrie RA and Goldman M. Validity of performance scales for disability assessment in multiple sclerosis. Multiple sclerosis. 2007; $13: 1176-82$

12. Learmonth YC, Motl RW, Sandroff BM, Pula JH, Cadavid D. Validation of patient determined disease steps (PDDS) scale scores in persons with multiple sclerosis. BMC Neurology. 2013;13:37.

13. Marrie RA, Cutter G, Tyry T, Vollmer T, Campagnolo D. Does multiple sclerosis-associated disability differ between races? Neurology. 2006;66(8):1235-1240.

14. Collins JG. Prevalence of selected chronic conditions: United States, 1986-1988. Vital Health Stat 10. 1993;(182):1-87.

15. Heesen C, Kasper J, Köpke S, Richter T, Segal J, Mühlhauser I. Informed shared decision making in multiple sclerosis - inevitable or impossible? J Neurol Sci. 2007;259(1-2):109-117.

16. Kasper J, Heesen C, Köpke S, Fulcher G, Geiger F. Patients' and observers' perceptions of involvement differ. Validation study on inter-relating measures for shared decision making. PloS One. 2011;6(10):e26255.

17. Charles C, Gafni A, Whelan T. Shared decision-making in the medical encounter: what does it mean? (or it takes at least two to tango). Soc Sci Med. 1997;44(5):681-692.

18. Anderson RM, Funnell MM. Patient empowerment: reflections on the challenge of fostering the adoption of a new paradigm. Patient Educ Couns. 2005;57(2):153-157.

19. Río J, Tintoré M, Sastre-Garriga J, et al. Change in the clinical activity of multiple sclerosis after treatment switch for suboptimal response. Eur J Neurol. 2012;19(6):899-904.

20. Castillo-Trivino T, Mowry EM, Gajofatto A, et al. Switching multiple sclerosis patients with breakthrough disease to second-line therapy PloS One. 2011;6(2):e16664.

21. Prosperini L, Gianni C, Leonardi L, et al. Escalation to natalizumab or switching among immunomodulators in relapsing multiple sclerosis. Mult Scler. 2012;18(1):64-71.
Patient Preference and Adherence

\section{Publish your work in this journal}

Patient Preference and Adherence is an international, peer-reviewed, open access journal that focusing on the growing importance of patient preference and adherence throughout the therapeutic continuum. Patient satisfaction, acceptability, quality of life, compliance, persistence and their role in developing new therapeutic modalities and compounds to optimize

\section{Dovepress}

clinical outcomes for existing disease states are major areas of interest for the journal. This journal has been accepted for indexing on PubMed Central. The manuscript management system is completely online and includes a very quick and fair peer-review system, which is all easy to use. Visit http://www. dovepress.com/testimonials.php to read real quotes from published authors. 